\title{
Visual ageism and the subtle sexualisation of older celebrities in L'Oréal's advert campaigns: a Multimodal Critical Discourse Analysis
}

\author{
Lame Maatla Kenalemang $^{1}$ \\ ${ }^{1}$ School of Humanities, Education and Social Sciences, Örebro University, Örebro, Sweden \\ Email: lame-maatla.kenalemang@oru.se
}

(Accepted 15 December 2020; first published online 19 February 2021)

\begin{abstract}
This study focuses on the recent increase in the use of older celebrities in cosmetics advertising. It asks what kinds of ideas and values these images may attribute to discourses of ageing. Drawing on a Multimodal Critical Discourse Analysis (MCDA) perspective, this study focuses on L'Oréal UK and Ireland Web advertisements, examining how these advertisements use older celebrities to redefine/reposition ageing and exploring how they relate to the notion of 'successful ageing'. In these advertisements, using cosmetics is presented as a positive, empowering choice. The advertisements simultaneously promote new discourses about ageing in which older women's sexuality is presented as a form of power. However, the analysis shows that the underlying discourse pathologises ageing and presents ageing as something which can be evaded through the consumption of cosmetics. It thus turns ageing into a choice, but one where the 'right choice' aligns with neo-liberal ideas about ageing well. For women, decision-making about ageing seems to be a never-ending process that requires constant construction, promoted through the older celebrity's sexualisation. Women are expected to always look good and present the best versions of themselves, even at the latest stages of life, which reproduces and legitimises sexist and ageist expectations about women's appearances, including the expectations that for older women to remain visible and attractive, they must hide outward signs of ageing.
\end{abstract}

Keywords: older celebrity; cosmetics advertising; successful ageing; Multimodal Critical Discourse Analysis; L'Oréal

\section{Introduction}

In recent years, there has been a significant increase in representations of older people in advertising (Ylänne, 2015). The rise of the 'commercialised retirement culture' (Katz, 2013) attests to the increasing importance of older people as a market segment and creates an opportunity for the emergence of new markets for anti-ageing products and services associated with the neo-liberal quest of 
'successful ageing' (see e.g. Kohlbacher et al., 2015; Sengès et al., 2019). Advertising has aligned itself correspondingly with this notion and has begun to promote the idea that ageing adults can foster a healthy, positive self-image. Accordingly, advertisements (adverts) are depicting older people who have dynamic lifestyles and who look relatively happy, healthy and youthful (Featherstone and Hepworth, 1995) or in Loos's (2013) terms, 'the eternally youthful seniors'. In this way, such adverts give false promises about ageing and force older people to construct themselves as ageless individuals (Minichiello et al., 2000; Ylänne et al., 2009). This portrayal of older people reproduces ageist attitudes, since older people who do not appear to age as 'successfully' as their peers become defined as people in need of fixing, forced to take control of their bodies - through consumption - to avoid social exclusion (Rozanova, 2010; Calasanti et al., 2012; Loos and Ivan, 2018). Older people, specifically older women, as they are drawn into the culture of consumption, are thus increasingly required to respond to new demands, imposing news forms of bodily discipline and self-surveillance that display commitment to resisting age through such practices as ... beauty interventions' (Twigg, 2018: 340). This subjects older women to the gaze of youth that evaluates them in terms of the ways their bodies fall short of the youthful ideal (Twigg, 2013). As Calasanti and Slevin (2006) point out, successful ageing for women in Western culture means maintaining the youthful appearance of the body. Hence, the older female face is made invisible - indicative of the 'unwatchability' of old age (Woodward, 1991). It is to no surprise then that traditionally, younger models tend to dominate adverts, even for products which are targeted specifically at older consumers, which suggests that older people offer a less-attractive appeal (Carrigan and Szmigin, 1998: 231). Recently, however, older female celebrities and models have become prominent figures in beauty and fashion campaigns; among these are Ellen DeGeneres for CoverGirl (2012), Joni Mitchell for Saint Laurent (spring 2015) and Joan Didion for Céline (spring 2015). In 2015, actresses Dame Helen Mirren (74), Jane Fonda (82), Julianne Moore (59), Isabelle Adjani (64), Iris Berben (69) and Vanessa Williams (57) featured in the French beauty products company L'Oréal 'Age Perfect' campaign. The aim of the campaign was to challenge the perceptions of ageing and promote the diversity of beauty after finding that 70 per cent of women over the age of 55 feel 'invisible in society', while 87 per cent said they felt under-represented in advertising and 81 per cent reported that they go unacknowledged by retailers (Pike, 2018). Does this represent change in the way older women are perceived?

Although there is extensive literature on the portrayal and representation of older people in advertising (see e.g. Ylänne et al., 2009; Chen, 2015; Prieler et al., 2015), very few studies focus specifically on how the construction of the older female celebrity is used to promote ideas about successful ageing and how this redefines how we understand ageing. To address this gap, this study focuses on the representation of older female celebrities in cosmetics advertising and how they are used to redefine/reposition ageing. The beauty field is one in which youth and young bodies are predominantly displayed and which is obsessed with erasing the past, unless it can be renewed for the present (Jerslev, 2018). By focusing on the representation of the female ageing face, this study sets out to understand the general cultural understanding of the female ageing face. Drawing on Multimodal 
Critical Discourse Analysis (MCDA) (see e.g. Machin and Mayr, 2012; Ledin and Machin, 2018, 2020), this study examines L'Oréal adverts aimed at mature women and addresses the following research questions:

- What kinds of ideas, values and identities about ageing do celebrities in the L'Oréal adverts communicate?

- What is the ideal way to age?

- What discourses of ageing are articulated through the L'Oréal adverts?

Through the analysis of these adverts, this study provides detailed information, invited by the textual and visual design of the adverts, on the way L'Oréal communicates ideas about what characterises successful ageing in present society and, by extension, the study offers insight into what cosmetics companies such as L'Oréal indicate ageing individuals should value.

\section{Ageing populations and the representation of older people in advertising}

Many Western societies are currently undergoing a demographic transition. Their rapidly ageing population is well documented, and projections show that by 2030 , one in six people will be 65 or over (United Nations, 2019). The notion of successful ageing (Rowe and Kahn, 1997, 2015) emerged as a response to population ageing and encourages older people to take responsibility for their wellbeing by engaging in forms of improvement and self-surveillance (Bordo, 1993), through lifelong investments in the body project (Shilling, 1993), which for women means 'fighting invisibility, resisting social exclusion and trying to maintain positive cultural capital' (Slevin, 2010: 1017, my italics). Such adverts are profitable and are a source of enormous profits, and continuously grow in resonance with the anti-ageing trend (Coupland, 2007; Loos et al., 2017). Hence, advertisers and marketers in consumer culture promote fear and insecurity about ageing appearances; at the same time, they provide aspirational models of possible ageless futures (Nabi, 2002): celebrities who endorse the products that claim age-delaying or even age-reversing properties. Such adverts draw upon cultural constructions of ageing within which individuals negotiate identities (Calasanti et al., 2012), and naturalise the imperative that all women must be beautiful, and that beauty is 'an essential part of a woman's identity, personhood and social success' (Johnston and Taylor, 2008). As Coupland (2007: 39) argues, skincare advertising texts have, therefore, become the locus of new discourses about ageing, culture, physiognomy, control and identity. These discourses reveal the different ways in which older women are positioned in society.

There is a vast amount of research on the portrayals of older people in various media, including advertising (Zhang et al., 2006; Williams et al., 2010). Most of the studies conducted have been from the United States of America and have included analyses of, for example, television programmes (e.g. Harwood and Anderson, 2002), television commercials (e.g. Lee et al., 2007) and print adverts (e.g. Robinson et al., 2008). Results from these studies suggest that older people, especially older women, are underrepresented in television and print adverts, relative to the percentage of older people in their population as well as to older men (Zhang et al., 2006). Research findings indicate that, on the one hand, there are 
portrayals of old age as a time of decrepitude, decline and dependency (Smythe, 2003), and on the other hand, positive representations - consonant with successful ageing - of being active, healthy and independent are increasing (Miller et al., 1999; Zhang et al., 2006; Williams et al., 2009; Loos and Ivan, 2018). Interestingly, however, these positive portrayals do not extend equally to both older men and women, as studies consistently find that older men are more likely to appear positively in adverts than older women (Zhang et al., 2006; Lee et al., 2007). However, as pointed out by Loos and Ivan (2018), such positive representations might lead to what they term 'visual ageism'. Visual ageism is used to describe the

social practice of visually underrepresenting older people or misrepresenting them in a prejudiced way ... this includes older adults being depicted in peripheral or minor roles without positive attributes; non-realistic, exaggerated, or distorted portraits of older people; and over-homogenized characterizations of older adults. (Loos and Ivan, 2018: 164)

If uncommon and inaccurate, this will lead to inaccurate feelings and perceptions of older people (Zhang et al., 2006).

Generally, most of the literature shows not only that older people often appear in adverts for products that are clearly associated with the anti-ageing battle - e.g. food and drinks, cosmetic treatments and surgery, exercise and therapy, and health products (Miller et al., 2004; Loos et al., 2017) - but also that these adverts stress the importance of combating incapacity in old age (Carrigan and Szimgin, 1999), forcing consumers continually to attempt to control age-related 'problems' or refuse to incorporate consumerist choices in their life as part of their wellbeing (Ylänne et al., 2009). Such adverts, thus, present youth as the ideal of physical beauty, athletic ability and good health, and mainly focus on maintaining good health and delaying and/or concealing the ageing process (Ylänne et al., 2009; Calasanti et al., 2012). By problematising ageing, such adverts treat ageing as a 'disease' that can be cured through the purchase of anti-ageing products (Coupland, 2007). In this way, such adverts pathologise the ageing body by suggesting that the appearance of ageing is undesirable.

\section{Age, celebrity and the body}

The discourse of ageing well is produced by consumerist marketing strategies that encourage older consumers to treat ageing as a life choice rather than a biological certainty (Loos et al., 2017; Loos and Ivan, 2018). The media and celebrities ('overtly public individuals' who are 'allowed to move on the public stage while the rest of us watch'; Marshall, 1997: ix) continually tell individuals that they are 'makeable', and that they can and must do something about who they are (Van den Bulck, 2014: 68). Marshall's (1997: 17) seminal account of celebrity shows that 'the individual continues to represent the ideological centre of capitalist culture' by promoting desire and providing consumers with 'compelling standards of emulation' (Rojek, 2001: 187). Rojek (2001: 189) argues that the ageing of celebrities does not necessarily threaten their influential role because 'the fan base ages with them'. As a result, 'celebrities function not only as objects of desire but as 
objects of nostalgia that can be further commodified by the market' (Rojek, 2001: 189). Yet, the primary function is not nostalgia, as Marshall and Rahman (2015) suggest. The scope has increased over the decades, and ageing celebrities are positioned to 'celebrate an active, vital, consumerist, senior life'; they are not simply 'nostalgic reminders of their or their audience's youth' (Marshall and Rahman, 2015: 580). As active, vital senior consumers, these ageing celebrities, I argue, encapsulate the notion of successful ageing.

The youthful body has become a focal point of people's self-image and obliges both female and male celebrities to maintain their bodies, including their beauty, continuously throughout their lives. The celebrity displays signifiers of successful ageing, plays a vital role in shaping social identities, and provides the mass audience - especially women - with advice, images and models that influence their construction of a 'personal lifestyle architecture'. The nature of the portrayal is such that great emphasis is placed on the body (Holmes and Jermyn, 2015: 17). Indeed, the body is considered to be a crucial indicator in the building and presentation of identity, image and lifestyle (Featherstone, 1991). The body, as such, is seen as a commodity - one that is 'editable' with the help of cosmetics and surgery that strengthen a certain image and portray a certain lifestyle (Van den Bulck, 2014: 71). Such editing is naturalised in advertising texts as a means to improve female facial appearance (see e.g. Coupland, 2007). The celebrity, therefore, functions as a socially appropriate vehicle to articulate and promote societal views of what is considered to be ideal beauty in Western culture. However, these images establish unrealistic standards of beauty that in reality are unattainable for most people and often cause women to feel that they need to 'fix' themselves. This feeling of imperfection can lead to dissatisfaction among many people and engender in them a stronger need to invest in their bodies (Richards et al., 2012; Del Rosso, 2017).

\section{Method and data: MCDA}

This study employs the theoretical perspective of Social Semiotics (see e.g. Machin and Mayr, 2012) and uses MCDA (see e.g. Machin and Mayr, 2012; Ledin and Machin, 2018, 2020) as its method of analysis. Drawing mainly on the work of Kress and van Leeuwen $(1996,2006)$, MCDA is a Social Semiotic approach to visual communication that allows us to break down compositions into their most basic components and then understand how these work together to create meaning (Machin, 2010). MCDA draws attention to how language and visual choices are used in actual contexts to identify the underlying ideas, values and identities that are used to communicate meaning, while also revealing the kinds of power interests buried in texts (Ledin and Machin, 2018). One of the key concepts in both Social Semiotics and MCDA is discourse. Foucault's (1977) concept of discourse is useful in understanding the dialectical relationship between ideology and power. In this study, discourse is understood as a 'recontextualisation of social practice', which is a way to describe how events are represented and reshaped in the interests of certain ideologies (see e.g. van Leeuwen, 2005). For example, in the context of this study, L'Oréal adverts communicate ideas and values about successful ageing that are signified through practices of consumption (e.g. use of anti-ageing creams). 
At the same time, however, the adverts construct the very discourses through which older women have come to understand 'success' and the importance of keeping an active/healthy lifestyle.

Social Semiotics focuses on the way that communicators use the semiotic resources available to them to achieve a specific communicative aim. For example, through both the use of language and other semiotic resources, such as fonts and colour, cosmetic adverts can be used to communicate discourses about the ideas and values of successful ageing. As such, Social Semiotics is interested in describing the available choices speakers use to communicate and shape how people and events are represented. For instance, Social Semiotics may consider which terms L'Oréal uses to describe older women or the actions they carry out. Another key concept used in this study is 'new writing' or 'integrated design', which relates to the way that semiotic resources are combined to communicate certain meanings (van Leeuwen, 2008; Ledin and Machin, 2018). The communicative choices in the L'Oréal adverts work together to communicate something about their 'Age Perfect' products and articulate why older consumers should consume these products. The focus of the analysis of the adverts undertaken is on how the different elements, such as colour (saturation, modulation, purity, co-ordination), settings, positioning of the viewer (gaze, pose, proximity), grammatical and lexical choices and iconography - as well as all these elements in combination - work to communicate particular ideas and values circulating in society and the reality in which people conceive the world. The study's focus, therefore, is on how L'Oréal adverts position older consumers as people who are making choices about ageing that show that they care about how they age.

A final key concept in this study is modality. The term 'modality' refers to semiotic resources indicating to what extent the content of a particular communication should be taken as true or real by the recipient (van Leeuwen, 2005). This study primarily deals with the modality of images; it aims to determine the modality value of the adverts and to examine how images signify their status as truth or fantasy, fact or fiction, etc., in order to communicate certain truths about the L'Oréal anti-ageing products (Kress and van Leeuwen, 2006). In most of the L'Oréal adverts, the top part of the page shows the 'promise' of the product: how youthfullooking older women will become if they buy the Age Perfect product. The bottom part of the page then provides factual information and the picture of the Age Perfect product itself. In such adverts, the modality value of the top and bottom tends to differ. The top part (the 'ideal') usually shows what the reader might or could be (relatively low modality) while the bottom part (the 'real') shows what is, that is, what the reader can actually purchase if they so choose (high modality). Increases and decreases in the degree to which certain means of visual expression are used (colour, sharpness, etc.) communicate an increase or decrease in the extent to which the image is meant to be considered 'real' (Machin and Van Leeuwen, 2007). The use of modality examined in this study helps L'Oréal to communicate certain truths (e.g. discourses of ageing well) and how these truths extend in Western contexts.

This study analyses two out of the $22 \mathrm{Web}$ adverts for products in the L'Oréal Paris Age Perfect range found on the company's UK and Ireland website. The UK and Ireland website and the two adverts were chosen because they feature 
the lead brand ambassador of L'Oréal, Dame Helen Mirren. Mirren is of interest to this study as her image is often used to represent examples of visible, attractive and successful older women who are acceptable to the public's gaze (Twigg, 2018). Moreover, the actress's beauty has been described by L'Oréal on their official Instagram account @lorealparis as 'timeless' and 'ageless'. It is, therefore, interesting to see how L'Oréal uses her image to embody successful ageing. Further, focusing on only two adverts gives a rich analysis of the data that will allow a more developed reading of the adverts. The following analysis highlights the discourses found in the adverts in which she appears. The underlying discourses relate to the broader social context in which the adverts exist to produce some insights into the particular ways in which L'Oréal describes older women and presents issues related to their ageing. The analysis focuses on text and images used in the adverts to interpret trends in the use of images of the older female celebrity as well as uncover the underlying ideas, values and meanings produced by these adverts.

\section{Analysis}

\section{The 'problem' of ageing}

L'Oréal adverts' narratives (see Figures 1 and 2) engage discursive strategies often referred to as the 'problem-solution pattern' (Hoey, 2001). These discursive strategies are used by L'Oréal to establish that ageing skin is a 'problem', and the advertised Age Perfect product is the 'solution' (Benwell and Stokoe, 2006). Such a narrative is typical of the images found in cosmetics adverts. In cosmetics advertising, the problem being highlighted is often some element related to the appearance of the female face (e.g. age spots, wrinkles, sagging). The idealised image of the female body in L'Oréal adverts is constructed through the face of a celebrity endorser. The problem-solution model takes as its starting point that older women need to 'perfect' the appearance of their skin through the purchase and use of Age Perfect anti-ageing creams (see e.g. Gill, 2007; Ringrow, 2016). The underlying discourse constructs visible signs of ageing as problems which can be 'cured'.

The structure of Figure 1 follows Kress and van Leeuwen's (2006) ideal/real composition. In the L'Oréal advert presented in this figure, the celebrity is placed at the top - in the 'ideal' position - and the Age Perfect product is positioned at the bottom, in the 'real' position. The text is also situated at the bottom of the composition and describes the problem of the appearance of ageing. The following analysis is based on textual data drawn from the advert in Figure 1. The text in the advert in Figure 1 is transcribed in Example 1, below.

\section{Example 1}

As skin becomes older and more fragile, it becomes more and more difficult to keep skin hydrated. Dehydrated skin feels dry and thin and can leave the complexion grey and dull leaving skin looking less radiant. L'Oréal Paris laboratories have formulated Age Perfect to help rejuvenate skin so that you can age gracefully. Proven science tested by leading skincare experts and scientists worldwide, captured in luxurious textures for a sumptuous skincare experience. Beautiful skin today and more youthful looking skin tomorrow. 
The above text describes what appears as the unwanted consequences of becoming older and includes negatively evaluative words to construct the appearance of the ageing female face. The text's reference to 'fragile', 'dry', 'thin', 'grey', 'dull' and 'less radiant' skin (Example 1, lines 1,2 and 3) suggests the problematic nature of the appearance of ageing. Terms such as 'fragile', 'dry' and 'thin' imply that the subject is damageable or easily broken, and are used to promote fear about old age and its associated changes in a person's body, such as wrinkling, sagging and thinning skin. This fear is not simply about 'looking old' but more complicatedly about not looking attractive. Such a discourse supposedly suggests that the use of anti-ageing products such as those advertised here is not only a legitimate but also a necessary part of maintaining physical attractiveness. Women are continuously urged to maintain their physical attractiveness, which Richards et al. (2012: 65) argue is tied to a youthful and sexualised ideal of beauty in Western society. The text's use of words such as 'grey', 'dull' and 'less radiant', with their associations with illness, is indicative of the unwatchability of old age (Woodward, 1991). The underlying suggestion is that the female body is 'unwatchable', and solutions must be found to counter or conceal visible signs of ageing (see e.g. Coupland, 2003, 2007). In this way, the ageing female face is treated as something that can be 'cured' through the purchase of anti-ageing products.

Naturally, the advertised anti-ageing product (see Figure 1) is presented as the 'solution' to the problems of ageing. The Age Perfect product is used to give credibility to the ideal, that is, the fantasy at the top (the celebrity). L'Oréal appropriates the ideas, values and meanings attached to the celebrity, i.e. Mirren's glamour and elegance, transferring them to their anti-ageing product. This process of transference makes use of a relationship which already exists in the mind of readers between the signifier (the celebrity) and signified (the appearance of youthfullooking skin) (see e.g. Williamson, 1978). In this way, the 'real' (Age Perfect product) can be seen to legitimise what lies in the 'ideal' (the celebrity).

Textually, the lexical choices 'rejuvenate', 'luxurious', 'sumptuous', 'beautiful' and 'youthful' in Example 1 (lines 4, 6 and 7) positively construct the appearance of ageing and emphasise how older women's skin looks or feels better after using anti-ageing products. Although the verb's roots are not explicitly mentioned in the text, the word 'rejuvenate' (line 4) and its etymological associations with things that have lost their youth, implies that the process of ageing is something that can and should be resisted. Older women are persuaded to assume responsibility for controlling or reversing visible signs of ageing, specifically through the purchase and use of the advertised 'corrective' solution. Women end up 'buying into' the pursuit of eternal youth presented to them through cosmetic adverts (Carrigan and Szmigin, 1999; Richards et al., 2012). A significant part of how this is achieved by the L'Oréal advert is through the company's claims to have engaged scientists in the manufacturing of their anti-ageing products, as in Example 1. In this text (Example 1), the lexical choices employed suggest that the solution offered is scientised: 'laboratories', 'formulated', 'proven science', 'experts' and 'scientists' (lines 3, 4 and 5). Age Perfect products are thereby immediately raised to the scientific category because they have been 'formulated' by 'leading skincare experts' and 'scientists' in 'laboratories'. The authoritative voice generated by the text's reference to scientific experiments validates the claims made by L'Oréal and helps legitimise 
older women's belief in the power of the anti-ageing products. The voice of science also lends 'moral authority' (Coupland, 2003: 132) to the advert by asking older consumers not to ignore the problems associated with ageing skin. Instead, the text persuades the reader to assume responsibility for their wellbeing (Ylänne et al., 2009) and to avoid social exclusion; thereby suggesting that good health in later life is fully the choice and responsibility of the individual and that older women who fail to 'successfully resist ageing' and embody a 'glamorous, ageless lifestyle' (Richards et al., 2012: 67) are somewhat to blame themselves for bad health. In these ways, the scientised solution offered makes older women feel enabled insofar as they believe that they have the means to be physically attractive and to appear to be youthful: 'beautiful skin today and more youthful looking skin tomorrow'.

Visually, the focal point of Figure 1 is the face of the celebrity, though, because she is décolleté, much of her neck and upper chest is also visible, as well as part of her arm. In the face must be met all internal expectations of beauty and, indeed, the face is the main canvas on which one can express one's true self (Coupland, 2003, 2007). Interestingly, however, the focus of the advertisement in Figure 1 shifts beyond the face and shows the celebrity's upper body, arm and hand as well. Such a decision may be because the designers intended to acknowledge the existence of the whole body rather than the more usual decontextualised face. The effect, encoded in the general message to the viewer, is that beauty does not reside only in the face but in the whole person as well, and could be a way to make older women embrace their ageing wholly. The image in Figure 1 describes how the celebrity uses the anti-ageing products to 'perfect' her appearance for 'more youthful looking skin'. The advert, thereby, uses the celebrity's visible management of ageing and how well they use the technologies that will allow youth to be extended through the face. As Lazar (2006) shows in her study of adverts addressed to young modern women in Singapore, for instance, such adverts suggest that women become empowered through their use of cosmetics. L'Oréal uses this discourse of empowerment to ask older consumers to redefine the meaning of age and its limitations by defying one's own signs of ageing, as part of ageing well or successfully resisting ageing (see e.g. Wada et al., 2015). Thus, the advert asks older consumers to identify with the celebrity and not only become complicit with the advert's empowering message that women in their fifties and older can be attractive and visible, but also reinforces the idea - one that the celebrity seems to embrace and endorse that beauty is endless work and a constant battle. However, this message seems to be contradictory as ageing women are asked to appear younger than they are to remain active and visible. Consequently, the text implies that for older women to be accepted in society as ageing gracefully or being 'successful agers', they should be both 'beautiful' and have 'youthful looking' skin.

The image of the celebrity in Figure 1 appears to be naturalistic; the face of the celebrity shows fine lines and wrinkles, which suggests that it has been left in its natural state. The softened pinkness of Mirren's cheeks and lips, with their natural contour lines revealed, further connote the visual impression of naturalness and lack of beautification. Such points signify that the image of the celebrity is a truthful reflection of reality. The advert thus represents the anti-ageing products' promise to correct or reverse visible signs of ageing. As the text assures, 'L'Oréal Paris 
laboratories have formulated Age Perfect to help rejuvenate skin so that you can age gracefully'. Despite the many features which give the image a realistic, natural effect, the low modality of the image also makes it appear idealised. The image in the advert (Figure 1) appears in an abstract, empty setting. The celebrity is shot against a nearly white background. The setting has been reduced to a white space, which means that it has been 'decontextualised' (Ledin and Machin, 2018). The absence of setting in the image lowers the modality and moves the image away from a naturalistic representation to a more idealised, abstract representation (Kress and van Leeuwen, 2006). As there is no concrete indicator as to where the celebrity is, the image can be more easily inserted into a variety of contexts, thus allowing it to acquire a conceptual feeling (Machin and Mayr, 2012). In the advert (Figure 1), both the celebrity and the anti-ageing product play a greater symbolic role (Ledin and Machin, 2018). The low articulation of the background's detail, as well as it being slightly out of focus, draws the attention of viewers directly towards the celebrity. This forced gaze is also generated by the bright, saturated lighting. The presence of bright light gives the effect of optimism, which is transferred to the Age Perfect products themselves. Further, the image of the celebrity is colour co-ordinated with the anti-ageing products; that is, the white colour of the celebrity's clothes and hair immediately link her to the Age Perfect products. The closely co-ordinated colours and the lowered modality in the advert work to reinforce the mood of the fantasy setting, well-removed from reality (see e.g. Machin and Thornborrow, 2006). The bright white lights and key lightening bathe the celebrity in an imaginary halo that makes her out as a momentarily spiritual being (Redmond, 2007), whom consumers should look up to, worship, which is further reinforced by her direct gaze.

The eyes of the celebrity appear to be almost level with those of the viewer. The effect of Mirren's direct gaze out of the page and on to the reader generates an immediate connection between viewer and viewed, an effect Kress and van Leeuwen (2006: 118) describe as generating a 'demand' image, that is, one in which a response is elicited or demanded from the reader. The warmth and directness of her gaze assumes a relationship with the reader based on intimacy and honesty, characteristics often regarded as central to female friendships (see e.g. Tannen, 2007). The celebrity's gaze invites the reader to desire her appearance, thereby positioning the viewer closer to her. The assumption of a personal relationship with the viewer is further reinforced by individualisation. The image of the celebrity in Figure 1 is shown as an individual and is one way to show that the agent in this situation acts alone. This has the effect of drawing the reader closer to Mirren and aligning the reader with her thoughts (Ledin and Machin, 2018). This image of a celebrity with no collective and no society, is a representational strategy that fits with the ideology of individualism that lies at the root of both Western consumerism (Machin and van Leeuwen, 2007) and neo-liberal ideas about successful ageing. This places responsibility on the individuals to be in complete control of their own lives and ageing process premised upon their consumption of cosmetic products.

As Machin states:

as with the given in given/new compositions, it is in the ideal top/bottom compositions that the underlying values of society are reaffirmed. So these are what we 
aspire to, what we want to be, or at least that which someone wishes to define as our aspirations. (Machin, 2010: 146)

In the context of this study, placing the face of the celebrity in the ideal composition implicitly aligns her with the ideal of female beauty, even though Mirren does not represent the typical image of models used in advertising. In this way, L'Oréal seeks to normalise the construction of ageing symbolised by the celebrity so that the image is received as one of ideal beauty - appearing youthful, slim, able bodied, White and middle class (LaWare and Moutsatsos, 2013).

While selling the anti-ageing product as a solution to a problem, the advert also suggests a second solution: ageing is a problem that can be 'cured' through lifelong investments in the body project (Shilling, 1993). These adverts in a sense pathologise ageing. As Ringrow (2016) states, the problem is defined within the current social context whereby youth continues to be privileged in many respects, while visible signs of ageing are considered undesirable and unattractive. The common assumption endorsed in such adverts is that women should be proactive in finding solutions for the physical effects of their ageing faces - solutions that would enable them to preserve the appearance of youthfulness (see e.g. Coupland, 2003, 2007). In such a context, women's bodies are treated as lifelong projects that need to be worked on constantly (see e.g. Lafrance, 2018). This selfimprovement often involves an attempt to disguise visual signs of ageing, which are constructed through negatively evaluative words. The text in the advert persuades consumers of two important things: (a) it is undesirable to appear to be ageing; and (b) older women must assume the responsibility of their wellbeing, tied to a youthful ideal of beauty, disguising their apparent ageing in order to achieve the ideal 'perfect' face. In the case of the latter, women can achieve a face in which they can find confidence. The relationship between purchasing Age Perfect products and attaining a 'desirable' ageing appearance is a construction that fits well within the neo-liberal context of successful ageing. For women, this means that the onus is on them to ensure their ageing bodies do not belie their age, which necessitates taking action to maintain the appearance of youth (LaWare and Moutsatsos, 2013). Consequently, L'Oréal assumes that older women who do not purchase and consume Age Perfect products - an action which is presented in these adverts as part of a lifestyle choice-cannot be truly ageing as 'perfectly' or successfully as the celebrity endorser in the advert, who herself embodies 'ageing well'.

\section{Discourses of sexual agency}

One of the most significant shifts in advertising in the last couple of years is the emphasis on women's sexual agency (Gill, 2003). Women are no longer represented as passive objects of the male gaze. Instead, they are now often represented as active, independent and sexually powerful (Gill, 2008). For older women, such changes are located within broader cultural shifts where remaining physically attractive and sexually active have become primary components of achieving successful ageing (see e.g. Wada et al., 2015). The L'Oréal adverts analysed here do not just work to empower older women to remain physically attractive and age successfully; 
they are also suggestive of sexual agency. The following section examines the visual and textual construction of female agency found in Figure 2.

The L'Oréal advert represents older women as active, sexual subjects who choose to present themselves in an objectified manner because it suits their 'liberation' (Gill, 2008) from old age, valorising the ultimately impossible goal of growing older without ageing. In the advert (Figure 2), the celebrity's smiling/teasing face, slightly parted lips, tousled hair and her unbuttoned loose shirt, revealing a bare neck and chest, draw on traditional notions of female sexuality and male desire. This is framed through a discourse of playfulness, freedom and, most importantly, choice typically found in younger women's magazines (see e.g. Machin and Thornborrow, 2006). Older women are represented as not seeking the approval of others (often and traditionally men), but as 'perfecting' themselves and in so doing potentially catching others' attention (Gill, 2008). Although much of this is never explicitly mentioned in the text, it is signalled in the image through the actions of the celebrity and how she engages with the viewer.

The image and pose of the celebrity are crucial for the look for approval. In Figure 2, the celebrity looks out of the frame and at the viewer. This modality of the gaze helps realise the traditional discourses about women, showing them as seductive or socially intimate. Through direct gaze, viewers are invited to take the place of the celebrity, visualising a reality in which they own the advertised antiageing product and the lifestyle it represents. In this context, direct gaze is also framed as a sexual proposition. As Reichert (2003: 18) explains, 'models behave sexually in ads by making eye contact with viewer'. Through her discussion of the absent or invisible man, Williamson (1978: 80) argues that the absence of a viewer in adverts is usually connected to sex. In the image (Figure 2), the celebrity is looking at a potential sexual partner. Her tilted head and fingers that gently rest on her neck and her provocatively unbuttoned shirt suggest that the invisible viewer is male. This reads as part of the fun, power and independence of women (see e.g. Machin and Thornborrow, 2006).

These discourses of sexuality are also realised textually in the advert, transcribed in Example 2.

\section{Example 2}

\section{TONE, TIGHTEN...UNBUTTON}

\section{REVEAL A LITTLE MORE...}

Why should your skincare stop at your face? Our new silky smooth rehydrating lotion with spf15 helps restore and protect even the most delicate areas of the skin. Say 'au revoir' to sagging and age spots. Skin feels nourished and looks far too smooth to keep under wraps.

Your perfect age...revealed.

The use of ellipses in the text in Example 2 - 'tone, tighten...unbutton' and 'reveal a little more...' (lines 1 and 2) - is suggestive of sexual acts (Williams, 2006). The 
ellipses suggest that some word(s) in the text have been left out for the readers to fill in. In this case, they note the elision of the 'unspeakable' sexuality and avoid showing older women in any explicit romantic or sexual way (see e.g. Williams et al., 2007). Although the reader cannot tell what has transpired in each ellipsis, the missing words are often implied by the context. In this advert, these ellipses are suggestive of the idea that, traditionally, because of the sexual taboos surrounding older people's sexuality, older women have had to keep their sexual desires hidden or invisible. Moreover, the metaphor 'keep under wraps' suggests that something is concealed or kept secret. Although it is unclear as to what exactly is concealed or kept secret, the rhetoric implicitly suggests that older women's sexuality was traditionally viewed with distaste and they were seen as asexual individuals who have finished with romance and sex (Williams et al., 2007). However, the verb 'reveal' (line 2) and its implications of something that has been made known, that is exposed, suggests - though it is not explicitly mentioned in the text - that older women's sexuality is no longer invisible. Such adverts challenge the taboo that elderly sexuality is 'unwatchable' (Woodward, 1991) and is here portrayed as sweet, playful and harmless. In this manner, L'Oréal appeals to middle-aged consumers who do not want to feel that their impending old age will bring a decline in attractiveness and sexuality (Williams et al., 2007). As Richards et al. (2012: 77) argue, this construction of the 'sexy oldie' versus 'asexual old age' is used by advertisers to depict older models who are ageing successfully or who are successfully resisting ageing.

Thus, the advert empowers older women to take charge of their sexuality, which it achieves subtly through the use of the verb 'unbutton'. The word 'unbutton' implies that someone is relaxed and is less inhibited. In the context of this advert, it can be used to indicate older women's independence, freedom and autonomy. The message is that these aspects of life can be achieved through the purchase of anti-ageing products. Therefore, the advert suggests that L'Oréal anti-ageing products empower older women with choices that allow them to express freely their sexuality more openly in public spaces - they are finally 'free' to explore more satisfying sexual relationships. Moreover, the use of French words in the advert is used to carry erotic connotations (see e.g. Piller, 2001). Although not explicitly mentioned in the advert, the words 'au revoir' as opposed to the translated English version 'goodbye' is associated with pervasive eroticism, given that French is made out to be the language of 'fun' and is equated with heterosexual eroticism (Piller, 2001). The 'fun fearless female' typically used to describe younger women (Machin and Thornborrow, 2006) now characterises this new, more sexually assertive construction of older women. Being fun and fearless is a way in which ageing women can achieve or maintain independence and power. Yet, although the representation of the active sexuality of older women is visible, women nevertheless remain partially covered by clothes. Therefore, the suggestion remains that older women and older people's sexuality in general is still distasteful (Walz, 2002). Seemingly, older women must disguise the signs of ageing, without appearing too young. At the same time, they must maintain an appropriately young-looking appearance and remain physically attractive without appearing overtly sexualised.

In the advert, the sexuality of older women is communicated in terms of their practice of self-determination and agency. First, older women's agency is confined 
to the aestheticisation of their appearance of ageing. Older women are expected to exercise control over their ageing bodies by correcting visible signs of ageing. Second, older women's agency is directly tied to consumerism. Older women's confidence and ability to act are grounded in their consumption of the advertised antiageing products. Lexically, the advert functions as the means by which something can be achieved, e.g. 'our new silky smooth rehydrating lotion with spf 15 helps restore and protect even the most delicate areas of the skin' (Example 2, lines 3, 4 and 5) ). Third, agency is represented as transformative. The verb 'help' in Example 2 (line 4) denotes constructive, transformative action. Through the use of 'synthetic personalization' (Fairclough, 1989: 62) achieved by the word 'your' (Example 2, line 3), older women are told that they possess the power to transform their looks and create new possibilities for ageing. This idealised notion of remaining sexually active and physically attractive alongside the discourse of ageing leads to a reconstruction of sexuality in later life. This new representation of sexuality represents freedom from the stereotype of asexuality, and opportunity. It also represents freedom to seek out new types of intimate relationships. However, these freedoms are not unbounded; there are restrictions. Those restrictions are in the form of being forced to conform, via a lifelong dedication to working on the body, to a narrow standard of beauty that demands such features as, for example, toned, tightened skin. Even though a more positive image of older women's sexuality is welcome in society, women's agency is still generally reduced to how a woman looks rather than how she acts (Machin and Mayr, 2012). In other words, women are still viewed through the male gaze.

\section{Conclusion: empowering or disempowering?}

The use of older celebrities, such as Mirren as the face of L'Oréal, shows a shift from a normative standard of beauty of younger models towards a more diversified standard of beauty that includes older models (LaWare and Moutsatsos, 2013). However, L'Oréal's negotiation of perceptions of ageing and beauty are undermined by its contradictory imperative to help older women embrace ageing and at the same time promote older women's consumption of products that encourage conformity to a youthful and sexualised ideal of beauty. In such adverts, older women's purchase and use of the anti-ageing products is presented as a positive, empowering choice (see e.g. Lazar, 2006; Johnston and Taylor, 2008). The adverts also claim to empower older women by granting them greater agency. This invokes a discourse of empowerment and self-improvement in which individual choice is crucial. Older women are now seemingly allowed to play with their sexuality, which can be seen as a positive change in society. However, these adverts come with a claim to empower women to be able to conceal visible signs of ageing, which is an indication of assuming responsibility for one's own wellbeing such that those who are unable to enjoy the so-called successful ageing are defined as somewhat unhealthy, unable and even irresponsible older women. This, in a sense, contradicts their message of empowerment, as the adverts seem to imply that only young-looking women are acceptable to the public gaze. Underlying this is a discourse which pathologises the appearance of ageing (problem) and treats the process of ageing as something that can be 'corrected' through the consumption of anti-ageing products (solution). 
Such a finding is in line with previous studies (see e.g. Coupland, 2007). This study supports the finding that adverts frame ageing as undesirable (see e.g. Calasanti, 2007). Such adverts are characterised by a discourse that sees ageing as a choice rather than a bodily function. These adverts indicate that traditional ideologies about women's identities have not changed. Although it seems that older women have more power and agency, the adverts suggest that for women, achieving these is a never-ending lifelong process that requires constant construction (Shilling, 1993), promoted through the celebrity's sexualisation. Women are expected to always look good and present the best versions of themselves until the very end. Therefore, although L'Oréal's advert campaigns seem to celebrate older women and diversity, at the same time they reproduce and legitimise sexist and ageist expectations about women's appearances, including the expectations that for older women to remain visible and attractive, they must hide the outward signs of ageing. Without the L'Oréal anti-ageing cream, the celebrity is unattractive and invisible, which is shown through the negatively evaluative words used to construct the appearance of the ageing female face. The L'Oréal campaign thus suggests that visibility and attractiveness in old age can be accessed through the purchase of L'Oréal cosmetic products. The relationship between using anti-ageing products and attaining a 'desirable' ageing appearance is a construction that fits well within the neo-liberal context of successful ageing. Paradoxically, these adverts use an older celebrity model to endorse Age Perfect products for older women. These adverts promote new discourses about ageing that represent older women's sexuality as a form of power signified through practices of consumption.

In conclusion, the adverts examined here are part of L'Oréal's 2015 Age Perfect campaign. Their websites contain multiple adverts offering stories about ageing. Analysing only two adverts produces a limited perspective of cosmetics advertising, however, it has also allowed for an in-depth analysis of the adverts. This study has focused on adverts aimed towards ageing women; future research could conduct a comparative study of adverts aimed towards ageing men and women for an interesting case for gender differences or similarities. Future research can also consider examining the perceptions of older women towards these adverts.

\section{References}

Benwell B and Stokoe E (2006) Discourse and Identity. Edinburgh: Edinburgh University Press.

Bordo S (1993) Feminism, Foucault and the politics of the body. In Ramazanoğlu C (ed.), Up Against Foucault: Explorations of Some Tensions Between Foucault and Feminism. London: Routledge, pp. 179-202.

Calasanti T (2007) Bodacious berry, potency wood and the aging monster: gender and age relations in anti-aging ads. Social Forces 86, 335-355.

Calasanti T and Slevin KF (eds) (2006) Age Matters: Realigning Feminist Thinking. New York, NY: Routledge.

Calasanti T, Sorenson A and King N (2012) Anti-ageing advertisements and perceptions of ageing. In Ylänne V (ed.), Representing Ageing. London: Palgrave Macmillan, pp. 19-35.

Carrigan M and Szmigin I (1998) The usage and portrayal of older models in contemporary consumer advertising. Journal of Marketing Practice: Applied Marketing Science 4, 231-248.

Carrigan M and Szmigin I (1999) In pursuit of youth: what's wrong with the older market? Marketing Intelligence and Planning 17, 222-230. 
Chen C (2015) Advertising representations of older people in the United Kingdom and Taiwan: a comparative analysis. International Journal of Aging and Human Development 80, 140-183.

Coupland J (2003) Ageist ideology and discourses of control in skincare. In Coupland J and Gwyn R (eds), Discourse, the Body and Identity. Basingstoke, UK: Palgrave Macmillan, pp. 127-150.

Coupland J (2007) Gendered discourses on the 'problem' of ageing: consumerized solutions. Discourse and Communication 1, 37-61.

Del Rosso T (2017) There's a cream for that: a textual analysis of beauty and body-related advertisements aimed at middle-aged women. Journal of Women and Aging 29, 185-197.

Fairclough N (1989) Language and Power. London: Longman.

Featherstone M (1991) The body in consumer culture. In Featherstone M, Hepworth M and Turner B (eds), The Body: Social Process and Cultural Theory. London: Sage, pp. 170-196.

Featherstone M and Hepworth M (1995) Images of positive ageing: a case study of Retirement Choice magazine. In Featherstone $M$ and Hepworth M (eds), Images of Ageing: Cultural Representations of Later Life. London: Routledge, pp. 29-47.

Foucault M (1977) Discipline and Punish: The Birth of the Prison. New York, NY: Pantheon Books.

Gill R (2003) From sexual objectification to sexual subjectification: the re-sexualisation of women's bodies in the media. Feminist Media Studies 3, 100-106.

Gill R (2007) Postfeminist media culture: elements of a sensibility. European Journal of Cultural Studies 10, $147-166$.

Gill R (2008) Empowerment/sexism: figuring female sexual agency in contemporary advertising. Feminism and Psychology 18, 35-60.

Harwood J and Anderson K (2002) The presence and portrayal of social groups on prime-time television. Communication Reports 15, 81-97.

Hoey M (2001) Textual Interaction: An Introduction to Written Discourse Analysis. London: Routledge.

Holmes S and Jermyn D (2015) Here, there and nowhere: ageing, gender and celebrity studies. In Jermyn D and Holmes S (eds), Women, Celebrity and Cultures of Ageing: Freeze Frame. London: Palgrave Macmillan, pp. 11-24.

Jerslev A (2018) The elderly female face in beauty and fashion ads: Joan Didion for Céline. European Journal of Cultural Studies 21, 349-362.

Johnston J and Taylor J (2008) Feminist consumerism and fat activists: a comparative study of grassroots activism and the Dove Real Beauty campaign. Signs: A Journal of Women in Culture and Society 33, 941-966.

Katz S (2013) Active and successful aging: lifestyle as a gerontological idea. Recherches Sociologiques et Anthropologiques 44, 33-49.

Kohlbacher F, Herstatt C and Levsen N (2015) Golden opportunities for silver innovation: how demographic changes give rise to entrepreneurial opportunities to meet the needs of older people. Technovation 39, 73-82.

Kress G and van Leeuwen T (1996) Reading Images: The Grammar of Visual Design. London: Routledge.

Kress G and van Leeuwen T (2006) Reading Images: The Grammar of Visual Design, 2nd Edn. London: Routledge.

Lafrance M (2018) Skin studies: past, present and future. Body and Society 24, 3-32.

LaWare MR and Moutsatsos C (2013) 'For skin that's us, authentically us': celebrity, empowerment, and the allure of antiaging advertisements. Women's Studies in Communication 36, 189-208.

Lazar MM (2006) 'Discover the power of femininity!' Feminist Media Studies 6, 505-517.

Ledin P and Machin D (2018) Doing Visual Analysis from Theory to Practice. London: Sage.

Ledin P and Machin D (2020) Introduction to Multimodal Analysis. London: Bloomsbury Publishing.

Lee MM, Carpenter B and Meyers LS (2007) Representations of older adults in television advertisements. Journal of Aging Studies 21, 23-30.

Loos E (2013) Designing for dynamic diversity: representing various senior citizens in digital information sources. Observatorio $\left(\mathrm{OBS}^{*}\right)$ 7, 21-45.

Loos E and Ivan L (2018) Visual ageism in the media. In Ayalon L and Tesch-Roemer C (eds), Contemporary Perspectives on Ageism. Cham, Switzerland: Springer, pp. 163-176.

Loos E, Ivan L, Fernandez-Ardevol M, Sourbati M, Ekström M, Wilinska M, Carlo, S and Schiau, I et al.(2017) Ageing well? A cross-country analysis of the way older people are visually represented on websites of organizations for older people. Journal of Comparative Research in Anthropology and Sociology 8, 63-83. 
Machin D (2010) Introduction to Multimodal Analysis. London: Bloomsbury.

Machin D and Mayr A (2012) How to Do Critical Discourse Analysis. London: Sage.

Machin D and Thornborrow J (2006) Lifestyle and the depoliticisation of agency: sex as power in women's magazines. Social Semiotics 16, 173-188.

Machin D and Van Leeuwen T (2007) Global Media Discourse: A Critical Introduction. Abingdon, UK: Routledge.

Marshall PD (1997) Celebrity and Power: Fame in Contemporary Culture. Minneapolis, MN: University of Minnesota Press.

Marshall BL and Rahman M (2015) Celebrity, ageing and the construction of 'third age' identities. International Journal of Cultural Studies 18, 577-593.

Miller PN, Miller DW, McKibbin EM and Pettys GL (1999) Stereotypes of the elderly in magazine advertisements 1956-1996. International Journal of Aging and Human Development 49, 319-337.

Miller DW, Leyell TS and Mazachek J (2004) Stereotypes of the elderly in U.S. television commercials from the 1950s to the 1990s. International Journal of Aging and Human Development 58, 315-340.

Minichiello V, Browne J and Kendig H (2000) Perceptions and consequences of ageism: views of older people. Ageing \& Society 20, 253-278.

Nabi RL (2002) Discrete emotions and persuasion. In Dillard JP and Pfau M (eds), The Persuasion Handbook. Thousand Oaks, CA: Sage, pp. 289-307.

Pike MR (2018) 'Getting old is not for pussies!' Helen Mirren and Jane Fonda lead all-star 'golden squad' for L'Oréal Paris - as the beauty giant recruits celebrities over 50 to help change perceptions of ageing. Mail Online, July 22. Available at https://www.dailymail.co.uk/femail/article-5979679/LOr-al-Parislaunches-golden-squad-stars-50.html.

Piller I (2001) Identity constructions in multilingual advertising. Language in Society 30, 153-186.

Prieler M, Kohlbacher F, Hagiwara S and Arima A (2015) The representation of older people in television advertisements and social change: the case of Japan. Ageing \& Society 35, 865-887.

Redmond S (2007) The whiteness of the Rings. In Bernardi D (ed.), The Persistence of Whiteness: Race and Contemporary Hollywood Cinema. Abingdon, UK: Routledge, pp. 91-101.

Reichert T (2003) What is sex in advertising? Perspectives from consumer behavior and social science research. In Reichert $\mathrm{T}$ and Lambiase J (eds), Sex in Advertising: Perspectives on the Erotic Appeal. New York, NY: Routledge, pp. 11-38.

Richards N, Warren L and Gott M (2012) The challenges of creating 'alternative' images of ageing: lessons from a project with older women. Journal of Aging Studies 26, 65-78.

Ringrow H (2016) The Language of Cosmetics Advertising. London: Springer.

Robinson T, Gustafson B and Popovich M (2008) Perceptions of negative stereotypes of older people in magazine advertisements: comparing the perceptions of older adults and college students. Ageing \& Society 28, 233-251.

Rojek C (2001) Celebrity. London: Reaktion Books.

Rowe J and Kahn R (1997) Successful aging. The Gerontologist 37, 433-440.

Rowe J and Kahn R (2015) Successful aging 2.0: conceptual expansions for the 21st century. Journals of Gerontology: Psychological Sciences and Social Sciences 70B, 593-596.

Rozanova J (2010) Discourses of successful aging in The Globe and Mail: insights from critical gerontology. Journal of Aging Studies 24, 213-222.

Sengès E, Guiot D and Chandon JL (2019) Desired ageing well: predictive validity for consumers aged 50-80. Recherche et Applications en Marketing (English Edition) 34, 2-27.

Shilling C (1993) The Body and Social Theory. London: Sage.

Slevin KF (2010) 'If I had lots of money ... I'd have a body makeover': managing the aging body. Social Forces 88, 1003-1020.

Smythe TC (2003) Growing old in commercials: not always a laughing matter. In Lester PM and Ross SD (eds), Images That Injure: Pictorial Stereotypes in the Media, 2nd Edn. Santa Barbara, CA: Praeger, pp. $167-172$.

Tannen D (2007) You Just Don't Understand: Women and Men in Conversation. New York, NY: Harper.

Twigg J (2013) Fashion and Age: Dress, the Body and Later Life. London: A\&C Black.

Twigg J (2018) Fashion, the media and age: how women's magazines use fashion to negotiate age identities. European Journal of Cultural Studies 21, 334-348. 
United Nations (2019) World Population Prospects: The 2019 Revision. New York, NY: United Nations Department of Economic and Social Affairs.

Van den Bulck H (2014) Growing old in celebrity culture. In Harrington CL, Bielby DD and Bardo AR (eds), Aging, Media and Culture. London: Lexington Books, pp. 65-76.

van Leeuwen T (2005) Introducing Social Semiotics. London: Routledge.

van Leeuwen T (2008) New forms of writing, new visual competencies. Visual Studies 23, 130-135.

Wada M, Clarke LH and Rozanova J (2015) Constructions of sexuality in later life: analyses of Canadian magazine and newspaper portrayals of online dating. Journal of Aging Studies 32, 40-49.

Walz T (2002) Crones, dirty old men, sexy seniors: representations of the sexuality of older persons. Journal of Aging and Identity 7, 99-112.

Williams L (2006) Of kisses and ellipses: the long adolescence of American movies. Critical Inquiry 32, $288-340$.

Williams A, Ylänne V and Wadleigh PM (2007) Selling the 'Elixir of Life': images of the elderly in an Olivio advertising campaign. Journal of Aging Studies 21, 1-21.

Williams A, Wadleigh $\mathbf{M}$ and Ylänne V (2010) Images of older people in UK magazine advertising: towards a typology. International Journal of Aging and Human Development 71, 83-114.

Williamson J (1978) Decoding Advertisements: Ideology and Meaning in Advertising. London: Marion Boyars.

Woodward K (1991) Aging and Its Discontents: Freud and Other Fictions. Bloomington, IN: Indiana University Press.

Ylänne V (2015) Representations of ageing in the media. In Twigg J and Martin W (eds), Routledge Handbook of Cultural Gerontology. London: Routledge, pp. 369-375.

Ylänne V, Williams A and Wadleigh PM (2009) Ageing well? Older people's health and well-being as portrayed in UK magazine advertisements. International Journal of Ageing and Later Life 4, 33-62.

Zhang YB, Harwood J, Williams A, Ylänne-McEwen V, Wadleigh PM and Thimm C (2006) The portrayal of older adults in advertising: a cross-national review. Journal of Language and Social Psychology $25,264-282$.

Cite this article: Kenalemang LM (2022). Visual ageism and the subtle sexualisation of older celebrities in L'Oréal's advert campaigns: a Multimodal Critical Discourse Analysis. Ageing \& Society 42, 2122-2139. https://doi.org/10.1017/S0144686X20002019 